\title{
GÉNERO E (IN)SUCESSO ESCOLAR: PERSPETIVAS DE PROFESSORAS/ES DO ENSINO BÁSICO SOBRE POSSÍVEIS CONSEQUÊNCIAS DA FEMINIZAÇÃO DO ENSINO ${ }^{1}$
}

\section{Resumo}

A presença crescente das raparigas nas escolas registada nos últimos anos, associada ao seu maior desempenho escolar em comparação com os rapazes, levou ao ressurgimento de alguma ansiedade social. A sobrerrepresentação das mulheres no corpo docente tem sido apontada como uma das razões para o menor desempenho escolar dos rapazes devido à ausência de role models masculinos. Numa perspetiva de género, este artigo apresenta uma reflexão sustentada por alguns resultados de um estudo que envolveu entrevistas indi-

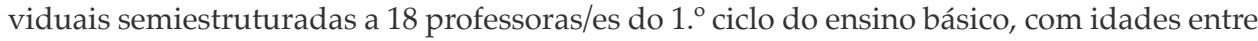
os 31 e os 61 anos, que entendem que a «feminização da docência» não afeta a oferta de educação de qualidade, e identifica diversos fatores que poderão contribuir para explicar o fenómeno do «in/sucesso escolar» dos/as alunos/as, como a falta de consciencialização sobre o género.

Palavras-chave: Género, educação, feminização da docência, docentes do ensino básico.

\begin{abstract}
Gender and school (un)success: perspectives of primary school teachers on possible consequences of the feminization of teaching

The growing presence of girls in schools registered in recent years, coupled with their greater school performance compared to their male peers, has led to the resurgence of some social anxiety. The overrepresentation of women in the teaching staff has been pointed out as one reason driving the poorer performance of male students due to the lack of masculine role models. From a gender perspective, this article presents a reflection supported by some results of a study that involved individual, semi-structured interviews with 18 male and female elementary school teachers between 31 and 61 years old, who understand that the «feminization of teaching» does not affect the provision of quality education, and identifies several factors that may contribute to explain the phenomenon of «school non/success» of male and female students, such as the lack of gender awareness.
\end{abstract}

Keywords: Gender, education, feminization of teaching, elementary school teachers.

\footnotetext{
1 Este trabalho foi financiado por fundos nacionais através da Fundação para a Ciência e a Tecnologia (Ref.: SFRH/BPD/78150/2011).

* Centro de Investigação e Intervenção Social, Instituto Universitário de Lisboa (CIS-IUL), ISCTE-Instituto Universitário de Lisboa, 1649-026 Lisboa, Portugal.

Endereço eletrónico: mhelena.rc.santos@gmail.com

Endereço Postal: CIS-IUL, ISCTE - Instituto Universitário de Lisboa, Av. a das Forças Armadas, 1649-026 Lisboa, Portugal.
} 


\begin{abstract}
Résumé
Genre et succès (ou échec): perspectives des enseignant.e.s du primaire âgés sur les conséquences possibles de la féminisation de l'enseignement

La croissante présence des filles dans les écoles enregistrées ces dernières années, associée à leur rendement scolaire supérieur, par rapport à leurs pairs masculins, a conduit à la résurgence d'une certaine anxiété sociale. La surreprésentation des femmes dans le corps enseignant a été identifiée comme l'une des raisons de la faible performance scolaire des garçons dû à l'absence de role models masculins. Dans une perspective de genre, cet article présente une réflexion soutenue par quelques résultats d'une étude portant sur des entretiens individuels semi-structurés avec 18 enseignant.e.s du primaire âgés de 31 à 61 ans, qui entendent que la «féminisation de l'enseignement» n'affecte pas la qualité de l'éducation, et identifie plusieurs facteurs qui peuvent contribuer à expliquer le phénomène de «l'in/succès scolaire» des étudient.e.s, comme le manque de conscience sur le genre.
\end{abstract}

Mots clés: Genre, éducation, féminisation de l'enseignement, enseignant.e.s des écoles élémentaires.

\title{
Introdução
}

A igualdade entre mulheres e homens tornou-se um objetivo das sociedades ocidentais, formalizado em muitas convenções, legislações e planos (Araújo 2010). Ao nível da educação, segundo o European Institute for Gender Equality, este é um dos objetivos fundamentais da política europeia (EIGE 2016), a qual tem levado a progressos no âmbito da igualdade de género em vários contextos. De facto, já em 2012, a OECD tinha confirmado progressos a nível mundial, incluindo em Portugal: as mulheres mostravam já um melhor aproveitamento escolar; que são mais empenhadas e prosseguem mais os estudos; apresentando percursos académicos mais longos e bem-sucedidos, exceto em engenharia, informática e arquitetura. Tal constitui uma grande mudança numa realidade que lhes era desfavorável (Ribeiro 2007). No mercado de trabalho, há já também uma sobrerrepresentação de mulheres em várias profissões masculinas, como são disso exemplo a medicina (Santos, Amâncio, e Roux 2015) e a política (Santos 2011).

Porém, persistem desigualdades de género, como mostram os dados sobre os Estados-membros da União Europeia (UE) (EIGE 2016) ou do relatório a nível global (World Economic Forum 2016). Segundo este último, embora a educação tenha sido a área em que mais se avançou (95\%), houve um retrocesso nos últimos tempos, permanecendo fossos de género que prejudicam a sociedade, sobretudo as mulheres. Neste contexto, é consensual que se deve apostar na educação, pois esta é «um catalisador para a mudança social e uma condição para a realização dos direitos humanos fundamentais» (EIGE 2016, 3). A escola e as/os professoras/es deverão estar entre os principais agentes de mudança, contribuindo para erradicar as desigualdades.

Contudo, também se verificam desequilíbrios de género na docência, estando as mulheres sobrerrepresentadas, sobretudo ao nível do ensino pré-escolar e 
básico. Esta «feminização do ensino» (Araújo 1990), associada ao maior desempenho/sucesso escolar das raparigas registado nos últimos anos, tem gerado alguma ansiedade social quanto ao futuro dos rapazes. O presente artigo centra-se nesta questão, ainda pouco explorada em Portugal, trazendo para o debate as perspetivas das/os professoras/es do 1 . $^{\circ}$ ciclo do ensino básico, discutidas à luz do quadro teórico desenvolvido a seguir.

\section{A segregação de género - o papel da educação}

As mulheres estão em maioria no ensino superior. Em Portugal, a presença das raparigas nos liceus começou a ser semelhante à dos rapazes na década de 1960 (Araújo 2010) e, 20 anos depois, a percentagem de mulheres nas universidades já era superior à dos homens (INE 2014). Em 2001, elas constituíam a maior parte da população licenciada $(56,6 \%)$, tendo-se diplomado mais mulheres na área da educação (86\%) do que homens (PORDATA 2016). Embora a percentagem de pessoas com um nível de escolaridade superior (21,5\%) seja, em 2016, mais baixa do que a média da UE, a percentagem de mulheres $(61,2 \%)$ manteve-se acima da dos homens (38,8\%) (PORDATA 2017). Porém, as mulheres diplomadas (59\%) continuam a estar sobrerrepresentadas em áreas como a educação (84\%), a saúde e a proteção social (78\%), e a estar sub-representadas nas áreas das engenharias industriais transformadoras (32\%), na linha da UE (EIGE 2016).

Apesar das elevadas taxas de sucesso escolar que se verificam nas mulheres, permanece uma segregação de género no mercado de trabalho a vários níveis, continuando estas a correr um maior risco de exclusão social, desemprego e empregos de baixa qualidade do que os homens (CITE 2013). Esta segregação dificulta quer a sua entrada nas áreas consideradas «masculinas» (e.g., matemática, ciência e tecnologia, e tecnologias da informação e comunicação), quer a opção deles pelas áreas consideradas «femininas» (e.g., educação, saúde, ciências sociais e humanidades). Uma das razões pelas quais esta situação ocorre, segundo o EIGE $(2016,5)$, é este rótulo persistente das áreas de estudo e de trabalho como sendo «femininas» ou «masculinas», nomeadamente nas escolas.

De facto, tal como outras organizações (Acker 1990), as escolas são genderizadas (Connell 2002; Williams 1995), constituem «regimes de género» inscritos em padrões mais alargados, que são a «ordem de género» vigente na sociedade (Connell 2002). Assim, nas suas práticas, muitas vezes, as escolas e as/os docentes preservam a ordem de género e fazem-no, nomeadamente, através da reprodução de estereótipos de género; de «formas sexistas de pensar, de ser e de estar», como referem Teresa Alvarez e Cristina C. Vieira $(2014,10)$. Segundo estas autoras, o sistema educativo reproduz os estereótipos sexistas aos seguintes níveis: i) do currículo e do conhecimento, ii) da formação de docentes, iii) das práticas pedagógicas, iv) da cultura organizacional, e v) da relação com a comunidade educativa. Por exemplo, ao nível das práticas pedagógicas, os estereótipos de género continuam 
presentes nos materiais didáticos e nas interações das/os professoras/es com os/ as alunos/as nas escolas, que também são influenciadas/os pelo género (Williams 1995). Assim, é essencial ir à origem do problema e apostar muito cedo na desconstrução dos estereótipos de género nas áreas da educação e da formação nos cinco níveis referidos.

A consciência deste problema por parte da UE já levou vários Estados-membros a aplicar diversos tipos de medidas para fazer face à segregação de género em diferentes áreas de estudo. Em Portugal, segundo Alvarez e Vieira (2014), a intervenção no sistema educativo tem sido feita, sobretudo, ao nível das práticas pedagógicas e dos materiais educativos. De facto, norteada pelos compromissos internacionais e nacionais assumidos por Portugal, a Comissão para a Cidadania e a Igualdade de Género (CIG) criou quatro guiões de Educação, Género e Cidadania e desenvolveu ações de formação de docentes e de intervenção em escolas-piloto (CIG 2010). Estes guiões destinam-se à educação pré-escolar (Cardona et al. 2010) ao primeiro (Cardona et al. 2011), segundo (Pomar et al. 2012) e terceiro (Pinto et al. 2009²) ciclos. Porém, importa ter em mente que criar instrumentos de apoio às/aos profissionais é insuficiente, sendo necessário apostar na sua formação para que os objetivos sejam, de facto, concretizados.

\section{A sobrerrepresentação das mulheres no ensino básico - que consequências?}

As diferenças nas escolhas de educação também se refletem na profissão docente. Embora a docência tenha começado por ser uma profissão masculina, hoje, as mulheres estão sobrerrepresentadas no ensino básico na maioria dos Estados-membros da UE (EIGE 2016). Em vários países do mundo (e.g., Austrália, Brasil, Inglaterra e EUA), a docência tornou-se uma profissão «feminizada» ainda no século XIX (e.g., ver Araújo 1990; Bailey e Graves 2016; Böhm e Campos 2013, sobre as causas do fenómeno). Em Portugal, essa tendência começou a desenhar-se ainda no século XIX (Araújo 1990, 81), tendo-se concretizado logo no final da primeira década do século XX (Nóvoa 1987, 594 apud Araújo 1990, 100), e assim permanecendo até à atualidade, como ilustra a Tabela 1 no caso do $1 .^{\circ}$ ciclo em Portugal $^{3}$.

2 De acordo com a ficha técnica da 2. ${ }^{a}$ edição (de 2015), a 1. a edição foi em 2009 (e não em 2010), conforme se pode verificar em https://www.cig.gov.pt/wp-content/uploads/2016/07/3Ciclo_Versao_Digital_FinalR.pdf

3 Alterações efetuadas de acordo com a fonte referida (Araújo 1990) nas páginas indicadas. Na pág. 100, os dados aqui referidos estão em nota de rodapé, onde se indica que a taxa de feminização no ensino básico era de 37,2\% em 1899/1900 e de 52,2\% em 1909/1910, e que os dados são de Nóvoa (1987: 594).

Na entrada bibliográfica, acrescentei a hiperligação para o artigo em causa: http://www.ces. uc.pt/rccs/index.php?id=405 
Tabela 1

Evolução do número e percentagem de docentes em exercício no $1 .^{\circ}$ ciclo do ensino básico, entre 1961 e 2015, por sexo

\begin{tabular}{ccc}
\hline Ano & Total & Percentagem de mulheres \\
\hline 1961 & 26087 & 87,3 \\
\hline 1970 & 29753 & 88,3 \\
\hline 1980 & 42501 & 91,8 \\
\hline 2001 & 39243 & 90,9 \\
\hline 2011 & 33044 & 86,3 \\
\hline 2015 & 28095 & 86,2 \\
\hline
\end{tabular}

Fonte: PORDATA (2016).

A investigação internacional confirma a perceção das escolas como «ambientes feminizados» (Skelton 2002, 77). O fenómeno gerou uma espécie de ansiedade social (Bailey e Graves 2016), apelando à entrada de mais homens no ensino básico (Coulter e McNay 1993; Skelton 2003) no sentido de contrabalançarem a «feminização» e servirem de role models masculinos aos rapazes (Drudy 2008; Skelton 2003). A base para esta preocupação parece estar relacionada com o facto de o número de raparigas estudantes ter aumentado (Bailey e Graves 2016), mas também porque elas têm tido um maior desempenho ou sucesso escolar do que os rapazes, levando a pensar que a «feminização da docência» beneficiaria as raparigas e os seus «estilos de aprendizagem», prejudicando os rapazes (Almeida 2002; Skelton 2003), que têm revelado uma relação mais frágil com a escola, manifestando menor empenho, maior desinteresse/abandono e insucesso (Cavaco, Alves, Guimarães e Feliciano 2015). A solução para superar esta «crise» da educação nos rapazes seria, então, aumentar o número de professores.

Em Portugal, Almeida (2002), que também revelou preocupação sobre esta questão, destacou algumas das razões identificadas nas ciências sociais para que ocorra um maior sucesso escolar das raparigas em comparação com os rapazes. Tal poderá dever-se: i) à maturidade mais precoce no desenvolvimento das raparigas; ii) ao resultado do cruzamento de duas instâncias socializadoras - a família e a escola. Nesta perspetiva, as crianças, quando chegam à escola, já passaram por um processo de socialização em casa (sendo as raparigas treinadas para qualidades como a disciplina, organização, obediência, contenção e capacidade de concentração) que beneficia as raparigas em termos de sucesso no sistema de ensino, mas não os rapazes (geralmente, socializados para a agressividade, a competição, o confronto, a conquista, o domínio da força física, a afirmação do eu e o desafio da autoridade); iii) às diferentes estratégias de socialização familiares adotadas para rapazes e raparigas, também relativamente ao papel desigual que o trabalho/ emprego tem na construção das suas identidades: eles são mais cedo pressionados para entrar no mercado de trabalho, ao contrário delas que, assim, ficam com mais 
tempo e espaço para se dedicar à escola; iv) à feminização do corpo docente da escola, já que, segundo Almeida, «a condição de género pode favorecer a criação de um sistema de laços, cumplicidades, e empatias implícitos entre professoras e alunas, desenhado uma arquitetura feminina de que beneficiam [...], sobretudo as raparigas» (2002: 17); e v) aos efeitos dos movimentos sociais e da emancipação das mulheres.

A solução proposta e a suposição de que o aumento de professores irá fornecer role models masculinos aos rapazes resultam de uma leitura simples de uma situação complexa e não têm sustentação empírica. De facto, grande parte da investigação internacional tem indicado que o sexo do/a docente tem pouco ou nenhum efeito no desempenho das/os estudantes (Sabbe e Aelterman 2007; Heilbig 2012). Além disso, a política educacional atual não desafia os estereótipos de género convencionais. É preciso facilitar modos alternativos de masculinidade e feminilidade através de uma «remasculinização» da educação (Skelton 2002). A solução proposta é sustentada por noções binárias e essencialistas, assentes nas teorias da socialização dos papéis de género que surgiram nas décadas de 1970/80. Ora, estas teorias têm sido criticadas, por assumirem que a masculinidade e a feminilidade estão localizadas apenas dentro dos corpos de homens e mulheres, respetivamente. Segundo Skelton (2003), por exemplo, esta forma unidimensional e essencialista de conceber o género não tem sido suficiente para compreender e explicar as diferenças que existem tanto entre os homens como entre as mulheres. Novas perspetivas sobre o género (e.g., Connell 1995, 2002) procuram ultrapassar esta lacuna, considerando a multidimensionalidade da identidade, ou seja, que as masculinidades e as feminilidades podem assumir várias formas, nomeadamente na intersecção com a classe social.

É neste contexto que, perante a escassez de estudos neste domínio em Portugal (Cavaco et al. 2015), realizámos um estudo exploratório com professoras/es do $1 .^{\circ}$ ciclo do ensino básico, com o objetivo de conhecer as suas perceções sobre esta realidade que está a gerar alguma preocupação social, também em Portugal.

\section{Perceções de professoras/es do $1 .^{\circ}$ ciclo do ensino básico}

Realizámos entrevistas individuais semiestruturadas a 18 professoras/es (8 mulheres e 10 homens) em atividade em 10 escolas básicas localizadas na área da Grande Lisboa e duas na Ilha da Madeira (sendo estas realizadas via Skype), com idades entre os 31 e os 61 anos $(M=44,06 ; D P=8,91)$.

Tratando-se de uma abordagem exploratória, recorremos a uma amostra de conveniência, sendo iniciada através do contacto pessoal das duas primeiras professoras entrevistadas (E1 e E2) e selecionada através da técnica de «bola de neve». As/os participantes receberam informações sobre os objetivos do estudo por email, sendo-lhes asseguradas as garantias de confidencialidade e anonimato. As entrevistas foram realizadas num local calmo (na sala de aula, de reuniões, ou 
na biblioteca), entre 21 de abril e 28 de julho de 2016, e demoraram entre 41 min e $1 \mathrm{~h} 43 \mathrm{~min}$. Com o seu consentimento, as entrevistas foram gravadas e, em seguida, transcritas na totalidade.

O guião englobou diversas questões sobre sexo, género e o ensino básico. Uma análise temática do material permitiu «identificar, analisar e relatar padrões (temas) dentro dos dados» (Braun e Clarke 2006, 79). Neste artigo, será considerado o material relativo aos temas abordados no quadro teórico, especificamente, sobre a prática do ensino no $1 .^{\circ}$ ciclo, considerando as perceções sobre as/os alunas/ os em sala de aula e no recreio, os pares (na forma como lecionam e na relação com as/os colegas), as razões para o in/sucesso escolar dos/as rapazes/raparigas, a «feminização da docência» e a resolução da situação, considerando o sexo (feminino, masculino) na análise.

Foram identificados cinco temas, designados da seguinte forma: 1) semelhanças e diferenças de sexo/género na sala de aula e no recreio; 2) semelhanças e diferenças de sexo/género no exercício da profissão e na relação com os pares; 3) expectativas, socialização de género, consciencialização das assimetrias e diferenças de sexo como fatores explicativos do in/sucesso escolar; 4) a «feminização» do ensino básico não afeta a qualidade da educação; e 5) a desfavorabilidade às quotas e à segregação do ensino como medidas promotoras da igualdade.

\section{Semelhanças e diferenças de sexo/género na sala de aula e no recreio}

Os resultados revelam que, na maioria das vezes, as/os entrevistadas/os percebem que as crianças se comportam de acordo com os estereótipos de género (Alvarez e Vieira 2014), salientando diferenciações entre rapazes e raparigas, a não ser ao nível da aprendizagem, em torno da qual há dúvidas sobre a existência de diferenças.

De facto, relativamente às professoras, com exceção de uma [E16], todas as entrevistadas percebem diferenças entre os alunos e as alunas relativamente às atitudes e comportamentos no início do $1 .^{\circ}$ ciclo, no recreio e na sala de aula. Em geral, percebem os rapazes como mais infantis, imaturos, físicos, gostando mais de corridas e de bolas e as raparigas como mais vaidosas, gostando mais de cuidar do físico, do visual, de saltar à corda, de dançar e de princesas. Admitem que tal é algo socialmente transmitido, seja pela sociedade em geral, seja pela família.

No entanto, as opiniões dividem-se relativamente à aprendizagem: umas não veem diferenças entre as raparigas e os rapazes [E10, E13, E16] e outras consideram que estas existem [E1, E2, E9, E12], embora entendam que são aprendizagens sociais e familiares que devem ser desconstruídas, inclusive pelas/os professoras/ /es. É, contudo, admitido que tal nem sempre acontece, pelo contrário, por vezes, «também é inculcado nas crianças» por elas/es [E1]. De facto, apenas duas professoras referem procurar esbater essas diferenças na escola, apostando na desconstrução de estereótipos de género (e.g., convidando os rapazes a brincar com 
bonecas [E1]; ou colocando as meninas e os meninos a jogar à bola e a fazer tricot [E2]), até porque admitem que estas diferenças acabam por influenciar a relação pedagógica no processo de ensino [E1, E9], embora outras pensem que não [E2, E3, E13, E16]. Dito isto, todas consideram que a sua relação com as/os alunas/os é igual, que a questão do sexo não influencia a relação pedagógica no processo de ensino:

Eu noto que as mães dos rapazes protegem-nos muito, fazem-lhes tudo [...]. Não estamos a falar de todas, mas estamos a falar de um grande grupo. Protegem-se mais os rapazes [...]. O que é que acontece na sala de aula? Eles são mais frágeis, são miúdos que não sabem pegar numa tesoura, são miúdos que não sabem fazer nada. [E3, Professora]

É igual, da professora para as meninas e da professora para os meninos. As diferenças são o que é que nós conversamos com eles que os motiva e o que conversamos com outras. Claro que eu acabo por, de alguma forma, ir mais ao encontro daquilo que elas gostam, que eu também sou menina [risos]. Portanto, conheço bem o ritmo e as conversas e, de alguma forma, os assuntos pelos quais elas têm interesse. Deles, não conheço tão bem, mas vou-me apoderando do conhecimento, não é? E, portanto, também vou, de alguma forma, cativando por aquilo que eles gostam. [E2, Professora]

Já os professores notam diferenças entre as raparigas e os rapazes, desde cedo, aos vários níveis: do desenvolvimento sociomoral, das aprendizagens, atitudes e comportamentos, pensando também que, a este nível, se trata de algo que é cultural, induzido pela família, que tem expectativas de que os rapazes sejam mais agressivos. De facto, percebem que, em geral, as raparigas têm um desenvolvimento mais acelerado do que o dos rapazes, tendo uma maior maturidade, autonomia, competências emocionais e sociais, sendo mais dóceis, obedientes, calmas, tranquilas, assertivas, aplicadas, organizadas, responsáveis, etc., e, como tal, no recreio, muitas vezes, sentam-se, escrevem, conversam, pensam em teatros, entre outras coisas neste registo. Já os rapazes têm comportamentos mais enérgicos, impõem a força física, criam mais conflitos, são mais agressivos, irrequietos, brincam à tourada, à bola, à apanhada e, na sala de aula, são mais distraídos, desconcentrados e instáveis.

Há uma agressividade que, às vezes, acontece naqueles meninos de oito, nove anos, sobretudo ao nível das brincadeiras. Às vezes, também transportam para dentro da aula, mas, muitas vezes, provêm do recreio. Mas é, sobretudo, aí, no recreio, em que, muitas vezes, há alguma agressividade, induzida culturalmente, induzida, muitas vezes, até pela família, pelo que esperam do rapaz ao nível da agressividade, ao nível da afirmação, etc. [E5, professor] 
Embora, entre estes, seja, em geral, admitido que as diferenças entre as raparigas e os rapazes influenciam a relação pedagógica no processo de ensino, entendendo que cabe às/aos professoras/es adaptarem-se às crianças, parecem ver esta realidade como algo que é inevitável, à qual vão procurando dar resposta o melhor possível. Mas em momento nenhum referem procurar desconstruir este tipo de comportamentos, recorrendo apenas a algumas estratégias no sentido de apaziguar o comportamento enérgico dos rapazes, para que tenham um maior desempenho escolar. É, por exemplo, referido que têm de «fazer sempre grupos com meninos e com meninas, porque, senão, seguramente, o grupo dos meninos [...] funcionaria muito pior» [E5].

Apenas dois entrevistados admitem que a questão do sexo/género também tem importância no caso do/a professor/a [E17, E18], admitindo que o professor é um pouco diferente para a rapariga e para o rapaz, notando também que os alunos se identificam mais com o professor e as alunas com a professora:

É diferente, não é? Nós, os rapazes, somos diferentes, é outro tipo de relação com o rapaz, é sempre mais aberta, mais fluente, porque, lá está, homem com homem, e mulher com mulher, é a forma, a ligação nota-se. Então, com crianças, é bastante notório, não é? [E17, Professor]

\section{Semelhanças e diferenças de sexo/género no exercício da profissão e na relação com os pares}

Há, igualmente, variações no grupo das professoras, no grupo dos professores e entre ambos os grupos quando questionadas/os sobre a relevância do sexo/ género dos profissionais de ensino, quer na forma como lecionam, quer na relação com os pares.

As entrevistadas que não notam diferenças na forma de ensinar/lecionar e na relação com as colegas entendem que a questão do sexo/género não influencia a forma de lecionar [E2, E9, E13], estando mais relacionada com as linhas pedagógicas e o programa; nem influencia a relação entre os pares, prendendo-se mais com a personalidade e as características pessoais de cada um/a:

Eu acho que tem a ver com linhas pedagógicas, muito sinceramente, não tem a ver com o facto de ser homem ou mulher [...]. Cada professor tem autonomia, tem inteira liberdade para, dentro da sua sala de aula, trabalhar segundo a sua metodologia, aonde se sente confortável. O programa é nacional, é igual, obviamente, mas eu posso seguir esse programa usando um manual ou não usando manual nenhum, não é? Tenho é que o cumprir. [E13, Professora]

As que notam diferenças nos dois níveis [E1, E2, E3, E9, E16] salientam, por exemplo, que, por vezes, as/os professoras/es canalizam os rapazes e as raparigas 
para diferentes espaços do recreio, limitando as suas brincadeiras; ou que, como os homens são mais fortes e têm uma postura diferente, têm mais capacidade de conseguir manter a ordem; ou, ainda, que, em termos relacionais, eles são mais idolatrados pelas mulheres:

Eu acho que o homem tem a capacidade de conseguir, em alguns casos, manter mais ordem. Mais, porque têm um vozeirão muito mais aprumado e conseguem, se calhar, mantê-los mais sossegados. [E12, Professora]

Há alturas em que os homens são muito idolatrados, sim. Então, há escolas, em que isso, então, é uma coisa, faz-me muita impressão. Quando aparece um homem [riso], às vezes, até tenho vergonha, sabe? Porque parecem as abelhas todas à volta do mel. [E3, Professora]

Entre os entrevistados, apenas dois [E6, E7] não notam diferenças entre homens e mulheres no exercício da profissão, considerando que a questão do sexo/ género não é importante na sala de aula, nem nas relações entre pares:

Não acho que seja importante. Eu acho que é... por exemplo, nas reuniões, eu sou muito combativo [...]. E há mulheres combativas nas reuniões. E quando sentem que alguma coisa vai mexer com a situação delas, levantam-se e falam. Ainda ontem, em relação à diretora do agrupamento, uma professora que se levantou, falou e disse que não concordava, pronto. Mas, por isso, a combatividade não tem a ver com o género. [E6, Professor]

Os que notam diferenças [E4, E5, E7] consideram que, em geral, os homens são mais objetivos, pragmáticos, e as mulheres são mais afetuosas, maternais, na linha dos estereótipos de género (Alvarez e Vieira 2014), que se, por vezes, podem ser benéficos para os homens nesta profissão dita «feminina» (e.g., chegam mais aos cargos de topo), em certas circunstâncias (e.g., no caso dos afetos e do toque), também podem ser nocivos. De facto, alguns professores percebem grandes diferenças na avaliação dos afetos manifestados por professores ou por professoras às/ aos alunas/os, admitindo que têm mais cuidado no relacionamento com as crianças. Por outro lado, também parecem ser benéficos para os rapazes, já que tendem a ser mais benevolentes com eles do que com as raparigas.

Na relação com os pares, também são apontadas diferenças que valorizam os homens, nomeadamente ao nível das conversas [E5, E8, E14, E18], percebendo que a dinâmica é facilitada pelo facto de eles gostarem de simplificar mais, por serem mais objetivos e pragmáticos. Contudo, parecem estar conscientes de que as diferenças entre homens e mulheres ligadas à questão da autoridade são socialmente determinadas, sendo benéficas aos homens, fazendo com que eles cheguem mais aos cargos de poder: 
$\mathrm{Eu}$, cuidado, tenho, por mim próprio, para não dar azo às pessoas para dizer: «Olha...». Muitas vezes, faço, ou dar um beijinho ou uma coisa, mas, se calhar, as outras pessoas podem achar que é outra coisa, não sei [...]. Acho que elas estão muito mais à vontade. Se for uma mulher a dar um beijinho a uma criança, acho que, pronto, aceitam... quem está de fora aceita muito melhor se for uma professora [...]. Com todos esses problemas da pedofilia, cada vez mais, isso tem, não é? Uma pessoa consciente tem que se prevenir, não é? [E7, Professor]

Eu até verifiquei o contrário, que as professoras, muitas vezes, tenderiam a compreender melhor as falhas dos meninos do que as das meninas [...] e desculpar menos a menina do que o menino. [E5, Professor]

Não são precisos muitos, se calhar, só um já chega em cada Conselho de Turma, ou assim... para ajudar a ser tudo um bocadinho mais objetivo [...]. A figura masculina, ainda é considerada como a figura, se calhar, de mais autoridade, mais agressividade [...]. Eventualmente, se há uma discussão, se se levanta um bocadinho mais a voz, se calhar, o homem é capaz de ser aquela pessoa que vai impor, ou que vai ser o elemento mais apaziguador. [E18, Professor]

Assim, é admitido por algumas professoras e professores que, por vezes, as/os docentes e as crianças são condicionadas/os em razão do sexo, limitando-se, na maior parte das vezes, a re/produzir a ordem de género convencional (Connell 2002; Williams 1995).

\section{Expectativas, socialização de género, consciencialização das assimetrias e diferenças de sexo como fatores explicativos do in/sucesso escolar}

Quando questionadas/os sobre as razões do maior sucesso escolar das raparigas em comparação com os rapazes, também se verificam discursos heterogéneos intra e intergrupais.

Entre as entrevistadas, há dois discursos prevalentes. Na linha de Almeida (2002), parecem, por um lado, considerar que o in/sucesso escolar resulta, em grande parte, do processo de socialização que ocorre no âmbito familiar (mas também escolar), que acaba por beneficiar as raparigas no sistema de ensino. Por outro lado, a consciência das raparigas sobre a existência de assimetrias de género desfavoráveis às mulheres leva-as, desde cedo, a perceber que têm de trabalhar para provar as suas competências.

De facto, é referido que o maior sucesso escolar das raparigas se prende com as expectativas que há relativamente a uns e a outras e com o que é avaliado na escola, entendendo que o sucesso das raparigas se prende com o que é exigido e com o modo como elas são preparadas para dar resposta ao que é exigido. No fundo, prende-se com o facto de elas terem de provar que são competentes e eles 
não. Portanto, o maior sucesso escolar das raparigas deve-se a elas próprias [E2, E9, E13, E16], à personalidade, maior investimento, concentração, responsabilidade, organização e dedicação ao trabalho das raparigas, que, para além disso, têm, como vimos, mais maturidade do que os rapazes, que são mais imaturos, despreocupados e trapalhões:

O sucesso das meninas tem que ver também com isto, que é exigido e como elas são preparadas para dar resposta ao que é exigido [...]. E, também, acho que tem que ver com isso de terem que provar muita coisa. Como eles não têm que provar tanta coisa, talvez fiquem [...], não são, se calhar, tão exigentes com eles próprios. [E1, Professora]

Os rapazes não se preocupam tanto. Só se estiverem mesmo os pais, que os obriguem e que os façam estudar e trabalhar, senão, eles estão muito desatentos e muito despreocupados [...]. As meninas, não, as meninas gostam. E, depois, gostam de usar as canetas de várias cores e são mais organizadas e são mais aplicadas. Eles, não, eles são trapalhões. [E16, Professora]

No caso dos entrevistados, percebem-se três tipos de discursos em torno da questão do in/sucesso escolar, apontando fatores genéticos e biológicos [E6, E7, 15], sociais e individuais. Com efeito, estes consideram que o maior sucesso das raparigas se deve às próprias raparigas, mas também aos rapazes e ao desenvolvimento de ambos, prendendo-se com o facto de elas atingirem mais cedo a maturidade do que eles, acabando por influenciar todos os níveis de ensino. Mas também está relacionado com o facto de elas serem mais persistentes, organizadas [E4] e empenhadas [E8], concentradas, metódicas, responsáveis [E17], atentas, cooperantes [E5] e mais predispostas à aprendizagem [E7] do que eles. Neste sentido, admitem que o programa possa estar mais ajustado à sua maturidade:

Eu acho que sim [nascem naturalmente assim], porque se são criados no mesmo ambiente, como é que, no mesmo ambiente, respondem de maneiras diferentes? Só pode haver alguma coisa, se calhar, genética, de características genéticas, que os faça... que sejam, a grande parte deles, desta maneira. Só pode ser, porque se até irmãos nós vemos, irmãos que, com a mesma idade, as raparigas atingem a maturidade muito mais cedo do que os rapazes. [E7, Professor]

Também entre os entrevistados, há quem considere que o maior sucesso escolar das raparigas se prende com as expectativas que há em relação a uns e a outras. Entendem que as raparigas percebem, desde cedo, que é esperado que elas tenham um comportamento mais cooperante e menos agressivo e correspondem, o que acaba por ser uma vantagem para elas na escola. Já os rapazes são estimulados a ser mais agressivos, a cooperar menos e ser mais competitivos e, em geral, também correspondem, tornando-se numa desvantagem para eles no sistema escolar. 
Mas o dito «insucesso» dos rapazes também pode ser uma questão de opção pessoal. Como têm mais facilidade no mercado de trabalho, alguns rapazes podem optar por desistir de estudar para irem para o mercado de trabalho e serem independentes, como referem dois professores [E8, E15]:

É esperado das raparigas que tenham um comportamento mais cooperante e menos agressivo. Isto transmite-lhes uma vantagem adicional logo nestes primeiros anos. Portanto, o facto de terem um comportamento mais cooperante traduz-se numa vantagem adicional em relação aos colegas, que são estimulados a ter mais agressividade, menor cooperação, mais competitividade. E estes estímulos iniciais, estes condicionamentos iniciais, dão uma vantagem, naturalmente, às meninas em relação aos rapazes. [E5, Professor]

Eu acho que o homem, o rapaz vá, se calhar, começa-se logo a interessar muito mais cedo pelo mercado de trabalho, para sua independência e, se calhar, afasta-se um pouco da escola. [E15, Professor]

\section{A «feminização» do ensino básico não afeta a qualidade da educação}

No geral, as/os entrevistadas/os revelam-se conscientes da sobrerrepresentação de mulheres no ensino básico, mas não consideram a situação problemática.

Entre as professoras, todas, exceto uma, que se mostra ambivalente (E12), se revelam seguras de que o maior sucesso das raparigas não está relacionado com a «feminização do ensino»; que os «ambientes feminizados» (Skelton 2002) não afetam a qualidade da educação e do ensino, entendendo que as/os professoras/es devem conseguir chegar a todas as crianças. E assim é, caso contrário, as raparigas não teriam mais sucesso quando são lecionadas por professores, como se verifica. Na linha de Almeida (2002), entendem que tal fenómeno estará antes relacionado com a questão da socialização de género, que, por um lado, ao privilegiar e apaparicar os rapazes na infância, onde lhes é exigido menos, acaba por se virar contra eles no sistema de ensino. Por outro lado, a consciencialização, por parte das raparigas, sobre as assimetrias de género existentes, leva-as, desde cedo, a perceber o que têm de fazer para se libertarem dessa «amarra»:

Eu acho é que... as miúdas, com muita tenra idade, percebem perfeitamente que há tratamentos diferentes $[\ldots]$. E percebem rapidamente o que é que têm que fazer para se libertarem daquela amarra e seguirem o seu caminho. E o seu caminho é este, é pela via académica, ponto final. [E13, Professora]

Também entre os entrevistados, nenhum, exceto um (que se revela ambivalente, E17), considera que o maior sucesso escolar das raparigas esteja relacionado com a «feminização» da profissão. Com efeito, entendem que esta não beneficia 
as raparigas, nem prejudica os rapazes [E15], admitindo mesmo que, a haver favoritismo, "se calhar, têm mais atenção pelos meninos do que pelas meninas» [E11]. A «feminização do corpo docente» não afeta a qualidade da educação, pois o ensino é igual; «os programas são impessoais», «são orientações do Ministério» [E6]. Entendem, portanto, que o in/sucesso se prende antes com o programa, com a forma como a escola está organizada [E4, E5, E7], com o modelo pedagógico e com a metodologia utilizada pelo/a professor/a [E7]. Em suma, «os moldes atuais do ensino favorecem os bons alunos» [E8], independentemente do sexo. A forma como a escola está organizada ainda é muito arcaica [E4]. Para se resolver esta situação, ora é sugerido que se atrase a entrada das crianças na escola [E7], ora que os programas sejam reduzidos, visto que podem, de facto, estar mais ajustados ao desenvolvimento das raparigas:

Eu creio que tem mesmo a ver com a organização do sistema educativo, tem mesmo a ver com a organização das escolas. [E5, professor]

O ajustamento dos programas, que são demasiado extensos, demasiado densos, demasiado complexos, e que, eventualmente, se as raparigas estiverem num índice maior, se calhar, podem perceber ou compreender mais rapidamente e isso depois reflete-se nos índices de sucesso. [E6, professor]

Assim, tal como a maior parte da investigação internacional (e.g., Heilbig 2012; Sabbe e Aelterman 2007), também estas/es professoras/os consideram que o sexo do docente tem pouco ou nenhum efeito no desempenho escolar das/os alunas/os.

\section{Desfavorabilidade às quotas e à segregação do ensino como medidas pro- motoras da igualdade}

Em geral, todas/os são favoráveis a um maior equilíbrio de género no ensino básico, mas manifestam-se contra a adoção de medidas como as quotas e a segregação do ensino.

As entrevistadas são favoráveis à entrada de mais homens na profissão (desde que por vocação e mérito pessoal) e a que haja uma maior diversidade de experiências, entendendo que quanto mais heterogéneas as pessoas forem, mais riqueza haverá no ensino. Porém, revelam-se totalmente contra a segregação do ensino:

Sou completamente contra [a segregação do ensino]. Lutaria, ia para a rua se fosse preciso. [E1, Professora] 
Quanto mais heterogéneas as pessoas forem, mais riqueza temos no ensino. Nós aqui temos 20 nacionalidades, portanto, mais riqueza que isto... e todos têm que aprender a tolerar e a respeitar, porque isso é que é importante. Nós não vivemos sozinhos e isolados do mundo. [E13, Professora]

Também os entrevistados salientam a relevância da diferença e do contacto da diferença, da referência masculina e feminina no ensino básico e não promovem [E11], ou são totalmente contra, a segregação no ensino, que só iria prejudicar as crianças e piorar os resultados dos rapazes. Esta ideia é percebida como um retrocesso, considerando que as/os alunas/os devem estar juntas/os para poderem partilhar as suas diferentes visões do mundo:

Eu sou a favor da diferença, do peso que a diferença tem, da riqueza que a diferença tem. [E4, Professor]

O trabalho a pares é uma coisa que eu valorizo muito. E se tenho meninas com melhores resultados do que meninos, a solução é que essas meninas consigam, de algum modo, auxiliar e ajudar os colegas que têm mais dificuldade, que é uma situação que, de resto, acontece com frequência [...]. Portanto, penso que esta diversidade que há, diversidade primeiro em termos de género e, depois, diversidade, também, em termos de experiências, de saberes, de tudo e mais alguma coisa, só enriquece e só beneficia [...]. Desse ponto de vista, ia-se criar meninas ainda mais, não é? E meninos ainda menos. [E8, Professor]

\section{Conclusão}

A opção por uma abordagem qualitativa, com recurso à análise temática dos discursos, sustentada por uma perspetiva de género, permitiu identificar uma pluralidade de perspetivas intra e intergrupos, mas também perspetivas comuns com consequências que importa salientar.

Permitiu, desde logo, concluir que existe uma consciência generalizada por parte de todas/os as/os entrevistadas/os sobre a sobrerrepresentação das mulheres no corpo docente do ensino básico, contudo, a mesma consciência não se verifica relativamente à influência do género das/os professoras/es no desempenho das alunas/alunos.

De facto, as/os entrevistadas/os consideram que a sobrerrepresentação das mulheres no ensino básico, que efetivamente existe, não é problemática, visto que não afeta a qualidade da educação nem do ensino. Portanto, na linha da investigação internacional (e.g., Heilbig 2012; Sabbe e Aelterman 2007), entendem que o sexo/género do profissional de ensino não tem nenhum efeito, ou que é pouco relevante, no desempenho escolar das/os alunas/os. 
A este propósito, importa acrescentar que, em Portugal, as escolas não são realmente «ambientes feminizados», como ocorre em países como a Inglaterra (e.g., Skelton 2002), porque continuam «masculinizadas», sobretudo ao nível dos cargos de topo. De facto, segundo a Direção-Geral de Estatísticas da Educação e Ciência, no ano letivo de 2015/16, entre os 789 cargos da direção de agrupamentos de escolas e de escolas não agrupadas do continente, 56,7\% foram ocupados por homens e 43,3\% por mulheres (DGEEC 2017). Portanto, em vez de uma «feminização» das escolas, percebe-se antes a persistência de uma assimetria de género (Araújo 2010) neste contexto, continuando o nível do poder e da tomada de decisão bastante «masculinizado» em termos de «regimes de gestão» (Mahony e Hextal 2000) e de organização.

Esta abordagem também permitiu verificar que há uma fraca consciencialização sobre os processos subjacentes às relações de género por parte da maioria das/ os 18 professoras/es entrevistadas/os, tendo revelado uma posição genderizada que contribui, na maioria das vezes, para a re/produção da ordem de género (Connell 2002) instalada na sociedade.

Embora se trate de um estudo com uma amostra pequena de entrevistadas/ os, com idades e em contextos profissionais um pouco diferentes, não permitindo, por isso, generalizar as opiniões e perceções expressas, é possível identificar alguns fatores nos seus discursos que poderão contribuir para ajudar a explicar o fenómeno do in/sucesso escolar, destacando-se: 1) os fatores genéticos e biológicos (com destaque para a questão da i/maturidade); 2 ) os fatores individuais (e.g., pode decorrer de uma opção individual, de desistir dos estudos ou de apostar neles); 3) os fatores sociais e culturais (destacando-se o processo de socialização, que acaba por beneficiar as raparigas no sistema de ensino); 4) os fatores organizacionais/contextuais (e.g., a forma como a escola está organizada, que ainda é arcaica; o modelo pedagógico utilizado; e o programa, que é complexo e extenso); 5) e os fatores ideológicos (e.g., o sucesso das raparigas pode dever-se à consciência das assimetrias de género existentes na sociedade), onde se enquadra a escassa consciencialização de género da maioria das/os professoras/es.

É, assim, imperativo apostar na mudança ao nível destes fatores, e não tanto através do combate à «feminização da docência» e de medidas, como as quotas ou a segregação de género, que só iriam prejudicar as crianças e piorar os resultados dos rapazes.

\section{Referências bibliográficas}

Acker, Joan. 1990. «Hierarchies, jobs, bodies: A Theory of gendered organizations». Gender and Society 4 (2): 139-158. DOI: https://doi.org/10.1177/089124390004002002

Almeida, Ana Nunes. 2002. «A sociologia, a escola e as questões do género». A Sociologia e o Ensino Secundário: Lugares, Saberes, Itinerários. Actas do Encontro Temático Intercon- 
gressos, 14-18. Oeiras: APS. Disponível em http://docplayer.com.br/44232205-A-sociologia-a-escola-e-as-questoes-do-genero-1.html [consultado em 20 de janeiro de 2017].

Alvarez, Teresa, e Cristina C. Vieira. 2014. «O papel da educação no caminho que falta percorrer em Portugal na desconstrução dos estereótipos de género: breves reflexões». Exedra (suplemento de 2014): 8-17. Disponível em http://www.exedrajournal.com/wpcontent/uploads/2014/12/sup14-8-17.pdf [consultado em 20 de fevereiro 2017].

Araújo, Helena Costa. 1990. «As mulheres professoras e o ensino estatal». Revista Crítica de Ciências Sociais 29: 81-103. Disponível em http://www.ces.uc.pt/rccs/index.php?id=405

Araújo, Helena Costa. 2010. «Escola e construção da igualdade no trabalho e no emprego». In A igualdade de mulheres e homens no trabalho e no emprego em Portugal: Políticas e circunstâncias, editado por Virgínia Ferreira, 217-245. Lisboa: CITE. Disponível em http:// cite.gov.pt/asstscite/downloads/publics/Igualdade_CITE_NET.pdf

Bailey, Lucy, e Karen Graves. 2016. «Gender and education». Review of Research in Education 40: 682-722.

Böhm, Bianca, e Míria Izabel Campos. 2013. «Atuação de professores homens na educação básica: um estado da arte sobre a produção acadêmica. Horizontes, Revista de Educação 1 (1): 59-72. Disponível em http://ojs.ufgd.edu.br/index.php/horizontes/article/ view/2044 [consultado em 10 de fevereiro 2017].

Braun, Virginia, e Victoria Clarke. 2006. «Using thematic analysis in psychology». Qualitative Research in Psychology 3 (2): 77-101. DOI: https://doi.org/10.1191/1478088706qp063oa

Cardona, Maria João (coord.), Conceição Nogueira, Cristina Vieira, Marta Uva e Teresa-Cláudia Tavares. 2010. Guião de Educação, Género e Cidadania: Pré-escolar. Lisboa: CIG.

Cardona, Maria João (coord.), Conceição Nogueira, Cristina C. Vieira, Isabel Piscalho, Marta Uva, e Teresa-Cláudia Tavares. 2011. Guião de Educação, Género e Cidadania: 1. ${ }^{\circ}$ Ciclo. Lisboa: CIG. Disponível em https://sigarra.up.pt/fpceup/pt/pub_geral. pub_view?pi_pub_base_id=15822

Cavaco, Carmen (coord.), Natália Alves, Paula Guimarães, e Paulo Feliciano. 2015. Abandono e insucesso escolar. Construir uma perspetiva de género. Lisboa: Instituto de Educação, Universidade de Lisboa. Disponível em www.poatfse.qren.pt/upload/docs/Relatorio_Final_Instituto_Educacao_UL.pdf [consultado em 17 de abril de 2015].

CIG - Comissão para a Cidadania e Igualdade de Género. 2010. «Nota Prévia». In Guião de Educação, Género e Cidadania: Pré-escolar, coordenado por Maria João Cardona, vii-viii. Lisboa: CIG.

CITE - Comissão para a Igualdade no Trabalho e no Emprego. 2013. Relatório sobre o progresso da igualdade entre mulheres e homens no trabalho, no emprego e na formação profissional - 2012. Lisboa: CITE. Disponível em http:/www.cite.gov.pt/asstscite/downloads/ Relat_iguald_homens_mulheres_12.pdf [consultado em 30 de junho 2015].

Connell, Raewyn. 1995. Masculinities. Cambridge: Polity Press.

Connell, Raewyn. 2002. Gender. Cambridge: Polity Press.

Coulter, Rebecca Priegert, e Margaret McNay. 1993. «Exploring men's experiences as elementar scool teachers». Canadian Journal of Education 18 (4): 398-413. DOI: https://doi. org/10.2307/1494940

DGEEC - Direção-Geral de Estatísticas da Educação e Ciência. 2017. «Diretores de agrupamentos de escolas e de escolas não agrupadas (N. $\left.{ }^{\circ}\right)$, segundo o sexo, por concelho». Disponível em http://www.dgeec.mec.pt/np4/home [consultado em 5 de julho 2017].

Drudy, Sheelagh. 2008. «Gender balance/gender bias: The teaching profession and the impact of feminization». Gender and Education 20 (4): 309-323. DOI: https://doi. org/10.1080/09540250802190156 
EIGE - European Institute for Gender Equality. 2016. Gender in education and training. Vilnius: EIGE. Disponível em http://eige.europa.eu/sites/default/files/documents/ti_ pubpdf_mh0216897enn_pdfweb_20170124120643.pdf [consultado em 20 de fevereiro 2017].

Heilbig, Marcel. 2012. «Boys do not benefit from male teachers in their reading and mathematics skills: empirical evidence from 21 European Union and OECD countries». British Journal of Sociology of Education 33 (5): 661-677. DOI: https://doi.org/10.1080/01425 692.2012.674782

INE - Instituto Nacional de Estatística. 2014. 25 de Abril - 40 anos de estatísticas. Lisboa: INE. Disponível em https://www.ine.pt/ine_novidades/25abr_pub_n/index.html [consultado em 26 de fevereiro 2017].

Mahony, Pat, e Ian Hextall. 2000. Reconstructing teaching. Standards, performance, and accountability. London: Routledge/Falmer.

Pinto, Teresa (coord.), Conceição Nogueira, Cristina C. Vieira, Isabel Silva, Luísa Saavedra, Maria João Silva, Paula Silva et al. 2009. Guião de Educação, Género e Cidadania: 3. ${ }^{\circ}$ Ciclo. Lisboa: CIG.

Pomar, Clarinda, Ângela Balça, Antónia Fialho Conde, Aitana Martos García, Alberto Martos García, Conceição Nogueira, Cristina C. Vieira et al. 2012. Guião de Educação, Género e Cidadania: $2{ }^{\circ}$ Ciclo. Lisboa: CIG. Disponível em https://sigarra.up.pt/fpceup/ pt/pub_geral.show_file?pi_gdoc_id $=572460$

PORDATA. 2016. «Educação. Docentes». Disponível em http://www.pordata.pt/Subtema/ Portugal/Docentes-43 [consultado em 18 de fevereiro 2017].

PORDATA. 2017. «Educação. Diplomados no ano». Disponível em http://www.pordata.pt/ Subtema/Portugal/Diplomados+no+Ano-42 [consultado em 18 de fevereiro 2017].

Ribeiro, Ana Maria Alves. 2007. "A vantagem escolar das raparigas no ensino secundário. Resultados escolares e identidades numa perspetiva de género». In Escola, jovens e média, organizado por Maria Manuel Vieira, 109-135. Lisboa: ICS.

Sabbe, Elien, e Antonia Aelterman. 2007. «Gender in teaching: A literature review». Teachers and Teaching: Theory and Practice 13 (5): 521-538. DOI: https://doi.org/ 10.1080/13540 600701561729

Santos, Maria Helena. 2011. Do défice de cidadania à paridade política: Testemunhos de deputadas e deputados. Porto: Edições Afrontamento.

Santos, Maria Helena, Lígia Amâncio, e Patricia Roux. 2015. «Numbers do not tell the whole story: Gender and medicine in Portugal». Women's Studies International Forum 53: 73-82. DOI: https://doi.org/10.1016/j.wsif.2015.08.005

Skelton, Christine. 2002. «'Feminisation of schooling' or 're-masculinising' primary education?» International Studies in Sociology of Education 12 (1): 77-96. DOI: https://doi. org/10.1080/09620210200200084

Skelton, Christine. 2003. «Male primary teachers and perceptions of masculinity». Educational Review 55 (2): 195-209. DOI: https://doi.org/10.1080/0013191032000072227

Williams, Christine. 1995. Still a man's world. Men who do women's work. London: University of California Press.

World Economic Forum. 2016. The Global Gender Gap Report 2016. Genève: World Economic Forum. Disponível em http://www3.weforum.org/docs/GGGR16/WEF_Global_ Gender_Gap_Report_2016.pdf [consultado em 26 de fevereiro 2017]. 
Maria Helena Santos. Doutorada em Psicologia Social e Organizacional pelo ISCTE-Instituto Universitário de Lisboa. É investigadora, bolseira de pós-doutoramento e membro integrado do CIS-IUL. Tem-se centrado nos estudos de género e nas medidas de ação positiva em profissões marcadamente masculinas (ex: política e medicina) e femininas (ex: enfermagem e ensino básico), no sentido de apurar se homens e mulheres enfrentam as mesmas consequências em contextos de minoria e como lidam com elas. Correio eletrónico: helena.santos@iscte.pt

Artigo recebido a 25 de maio de 2017 e aceite para publicação a 30 de setembro de 2017 
